\title{
EFFECT OF FATIGUE ON EXPLOSIVE STRENGTH AND MUSCLE ARCHITECTURE OF THE VASTUS LATERALIS
}

\author{
EFEITO DA FADIGA NA FORÇA EXPLOSIVA E ARQUITETURA MUSCULAR DO VASTO LATERAL
}

Original Article

ARTIGO ORIGINAL Artículo Original

\author{
EFECTO DE LA FATIGA SOBRE LA FUERZA EXPLOSIVA Y LA ARQUITECTURA MUSCULARDEL VASTO LATERAL
}

\begin{abstract}
Matheus Martins de Sousa' (D) (Physiotherapist)

Conrado Torres Laett ${ }^{1,2}$ (iD) (Physical Education Professional) Ubiratã Faleiro Gavilão $0^{1,2}$ (D) (Physical Education Professional) Rodrigo Araújo Goes 3 (D) (Orthopedic Doctor)

Carlos Gomes de Oliveira² (D) (Electronic Engineer)

Lenifran de Matos Santos ${ }^{4}$ (DD (Physical Education Professional) Sidnei Cavalcante da Silva ${ }^{4,5}$ (D) (Physical Education Professional) Victor Rodrigues Amaral Cossich 1,2,4 (iD (Physical Education Professional)
\end{abstract}

\section{Instituto Nacional de} Traumatologia e Ortopedia (INTO), Neuromuscular Research Laboratory, Research Division, Rio de Janeiro, RJ, Brazil. 2. Universidade Federal do Rio de Janeiro (UFRJ), School of Physical Education and Sports (EEFD), Biomechanics Laboratory, Rio de Janeiro, RJ, Brazil.

3. Instituto Nacional de

Traumatologia e Ortopedia (INTO), Center for Sports Trauma, Rio de Janeiro, RJ, Brazil.

4. Instituto Nacional de

Traumatologia e Ortopedia (INTO), Research Laboratory in Exercise

Physiology, Research Division, Rio de Janeiro, RJ, Brazil.

5. Universidade Salgado de Oliveira (UNIVERSO), Postgraduation Program in Activity Sciences, Niterói, RJ, Brazil.

\section{Correspondence}

Victor Cossich

PhD. Instituto Nacional de

Traumatologia e Ortopedia (INTO).

Av. Brasil, 500, Caju, Rio de Janeiro,

RJ, Brazil. 20940-070.

victor.cossich@gmail.com

\begin{abstract}
Introduction: There has been little research on changes in rate of torque development (RTD) and muscle architecture. This study evaluated the effect of fatigue on RTD and muscle architecture of the vastus lateralis (VL). Methods: Seventeen volunteers $(25.5 \pm 6.2$ years; $177.2 \pm 12.9 \mathrm{~cm} ; 76.4 \pm 13.1 \mathrm{~kg})$ underwent isokinetic knee extension assessment at $30 \%$ to obtain the peak torque (PT-ISK), before and after a set of intermittent maximal voluntary isometric contractions (MVIC) (15 reps $-3 \mathrm{~s}$ contraction, $3 \mathrm{~s}$ rest) used to promote muscle fatigue, monitored by the median frequency (MDF) of the electromyography from the $\mathrm{VL}$, rectus femoris and vastus medialis muscles. Before and after the fatigue protocol, ultrasound images of the VL were obtained to measure muscle thickness (MT), fascicle length (FL), and fascicle angle (FA). The peak isometric torque (PT-ISM) and the RTDs in 50 ms windows were calculated for each MVIC. The RTDs were reported as absolute values and normalized by the PT-ISM. Results: Fatigue was confirmed due to significant reductions in MDF in all three muscles. After the fatigue protocol, the PT-ISK was reduced from $239.0 \pm 47.91$ to $177.3 \pm 34.96 \mathrm{Nm}$, and the PTMVIC was reduced from $269.5 \pm 45.63$ to $220.49 \pm 46.94 \mathrm{Nm}$. All the RTD absolute values presented significant change after the fatigue protocol. However, the normalized RTD did not demonstrate any significant differences. No significant differences were found in the muscle architecture of the VL. Conclusions: The reduction in explosive strength occurred concomitantly with the reduction in maximum strength, as evidenced by the lack of changes in normalized TDT. Level of Evidence III.
\end{abstract}

Keywords: Muscle strength; Isokinetic Dynamometer; Fatigue; Ultrasonography; Quadriceps muscle; Knee.

\section{RESUMO}

Introdução: Alterações na taxa de desenvolvimento de torque (TDT) e arquitetura muscular causadas pela fadiga são temas pouco investigados. Esta pesquis a avaliou o efeito da fadiga na TDT e arquitetura muscular do vasto lateral (VL). Métodos: Dezessete voluntários (25,5 $\pm 6,2$ anos; $177,2 \pm 12,9 \mathrm{~cm} ; 76,4 \pm 13,1 \mathrm{~kg}$ ) realizaram avaliação isocinética de extensão do joelho em 30\%s para obtenção do pico de torque (PT-ISK) antes e após uma série de contrações voluntárias isométricas máximas (CVIM) intermitentes (15 reps - 3 s contração, 3 s intervalo) utilizadas para causar fadiga muscular, monitoradas pela frequência mediana (FMD) da eletromiografia do VL, reto femoral e vasto medial. Antes e após o protocolo de fadiga, imagens de ultrassonografia do VL foram obtidas para mensuração da espessura muscular, comprimento de fascículo e ângulo do fascículo. O pico de torque isométrico (PT-ISM) e TDTs em janelas de 50 ms foram calculados para cada CVIM. As TDTs foram calculadas em valores absolutos enormalizadas pelo PT-ISM. Resultados: A fadiga foi confirmada devido a reduções significativas da FMD dos três músculos. Após a fadiga, o PT-ISK foi reduzido de 239,0 \pm 47,91 para 177,3 $\pm 34,96 \mathrm{Nm}$, e o PT-CVIM de 269,5 $\pm 45,63$ para 220,49 $\pm 46,94 \mathrm{Nm}$. Todos os valores de TDT absolutos apresentaram-se significativamente diferentes após o protocolo de fadiga. Contudo, as TDTs normalizadas não demonstraram diferença significativa. Não foram observadas diferenças significativas na arquitetura muscular do VL. Conclusões: A redução da capacidade explosiva ocorreu de maneira concomitante com a redução da força máxima evidenciada pela falta de alterações na TDT normalizada. Nível de Evidência III.

Descritores: Força muscular; Dinamômetro Isocinético; Fadiga; Ultrassonografia; Músculo quadriceps; Joelho.

\section{RESUMEN}

Introducción: Los cambios en la tasa de desarrollo del torque (TDT) y la arquitectura muscular causada por la fatiga son temas poco investigados. Esta investigación evaluó el efecto de la fatiga en la TDT y la arquitectura muscular del vasto lateral (VL). Métodos: 17 voluntarios (25.5 \pm 6.2 años; $177.2 \pm 12.9 \mathrm{~cm} ; 76.4 \pm 13.1 \mathrm{~kg})$ se sometieron a una evaluación isocinética de la extensión de la rodilla a 30\%/s para obtener el pico de torque (PT-ISK), antes y después de una serie de contracciones voluntarias máximas intermitentes (CVIM) (15 repeticiones - contracción 3 s, intervalo $3 \mathrm{~s}$ ) utilizadas para causar fatiga muscular, monitoreadas por la frecuencia media (FMD) de la electromiografía VL, recto femoral y vasta medial. Antes y después del protocolo de fatiga, se obtuvieron imágenes de ultrasonido VL para medir el grosor muscular, la longitud del fascículo y el ángulo del fascículo. Se calculó el par isométrico máximo (PT-ISM) y las TDT en ventanas de $50 \mathrm{~ms}$ para cada CVIM. Las DTT se calcularon en valores absolutos y se normalizaron mediante 
PT-ISM. Resultados: la fatiga se confirmó por reducciones significativas en la fiebre aftosa de los tres músculos. Después de la fatiga, el PT-ISK se redujo de $239.0 \pm 47.91$ a $177.3 \pm 34.96$ Nm, y el PT-CVIM de $269.5 \pm 45.63$ a $220.49 \pm 46.94$ $\mathrm{Nm}$. Todos los valores absolutos de TDT fueron significativamente diferentes después del protocolo de fatiga. Sin embargo, las TDT normalizadas no mostraron diferencias significativas. No se observaron diferencias significativas en la arquitectura muscular de la LV. Conclusiones: La reducción en la capacidad explosiva ocurrió simultáneamente con la reducción en la fuerza máxima, evidenciada por la falta de cambios en la TDT normalizada. Nível de evidencia III.

Descriptores: Fuerza muscular; Dinamómetro Isocinético; Fatiga; Ultrasonografía; Músculo cuádriceps; Rodilla.

\section{INTRODUCTION}

Muscle strength is commonly measured through the maximum strength. ' However, much time is required for a muscle group to generate maximum strength when compared to the demands in everyday and sporting situations. ${ }^{2-4}$ For instance, the available time to produce strength during running and jumping varies between $80-200 \mathrm{~ms}^{5,6}$ highlighting the ability to produce strength in short periods of time, the explosive strength. ${ }^{2,3}$ The explosive strength may be assessed through the rate of torque development (RTD), 2,3,7 obtained by the ratio of the produced torque from an isometric maximal voluntary contraction (MVC) by an established period of time, generally between 50 and $250 \mathrm{~ms}^{2,8,9}$ as well as the maximum RTD value (MRTD) reached by calculating the derivative of the torque signal. ${ }^{10,11}$ The RTD may be subdivided as early $(\leq 100 \mathrm{~ms})$ and late ( $\geq 200 \mathrm{~ms}$ ). Early RTD is strongly influenced by recruitment threshold and firing rate of motor units, ${ }^{12,13}$ while structural factors of the musculotendinous unit and the maximum strength have a greater influence on late RTD. ${ }^{14}$ It is possible to compare different individuals and/or muscle groups when the RTD is normalized by the maximum strength, without the influence of maximum strength as bias. $^{2}$

Muscle fatigue may be defined as the reduction of the muscle capacity to produce a strength level. ${ }^{15}$ The increase of energy demand and muscle acidity, along with the decrease of substrate reserves, prevent adequate resynthesis of adenosine triphosphate (ATP). ${ }^{15,16}$ ATP is necessary for the cross-bridges formation, explaining the drop in strength under fatigue. ${ }^{16}$ The median frequency (MDF) is a spectral analysis of the electromyography signal (EMG) that has been utilized as a physiological marker of muscle fatigue. ${ }^{15,17}$ The reduction in FMD is associated with, a decrease in the muscle fibers conduction velocity due to the increase in local acidosis. ${ }^{17}$ In fact, studies observed that fatigue causes a decrease in MDF. ${ }^{18}$ Studies have been conducted to understand the effects of fatigue on explosive strength, but the topic is still an open debate. Bearing in mind that individuals with higher RTDs may be less susceptible to the occurrence of injuries, ${ }^{19}$ assessing the effect of fatigue on RTD is important for coaches, physiotherapists, and sports doctors seeking strategies to reduce the risk of injuries.

Muscle architecture, defined by the number and placement of fascicles within the muscle, is one of the main determinants of the ability to produce strength. ${ }^{20,21}$ Studies have reported acute changes in the length and inclination of the vastus lateralis $(\mathrm{VL})$ fascicles after one set of leg press performed explosively until fatigue ${ }^{22}$ and after maximum cycle ergometer test. ${ }^{23}$ There was an increase in muscle thickness (MT) and fascicle angle (FA) in both studies. Furthermore, Csapo et al. ${ }^{22}$ found $1 \%$ decrease in fascicle length (FL). Mitsukawa et al. ${ }^{24}$ evaluated the effect of 60 intermittent plantar flexion MVCs on the soleus and medial gastrocnemius, which increased $13 \%$ and $22 \%$ in FL, respectively. Taken together, the results suggest that acute structural changes may occur due to muscle fatigue, but the effects of these changes on muscle strength, especially on explosive strength, are not clear yet.

Thus, the aim of this study was to investigate the acute effect of muscle fatigue caused by one set of intermittent MVCs on knee extension RTDs and the muscle architecture of the VL. It was hypothesized that the fatigue results in significant reductions in maximum strength and absolute RTD concomitantly. However, the same should not be observed for normalized RTD.

\section{MATERIALS AND METHODS}

\section{Participants}

Seventeen subjects participated in the study (13 men - age (mean \pm DP): $25.5 \pm 6$ years, height: $177.2 \pm 12.9 \mathrm{~cm}$, and total body mass: $76.4 \pm 13.1 \mathrm{~kg}$ ). Only subjects classified as "active" and "very active" were included in the sample. ${ }^{25}$ Those who reported orthopedic injuries or a history of lower limb surgery were excluded. The study was approved by the Ethics and Research Committee (CAAE:93764818.6.0000.5273) and all participants were informed about the study procedures and given the written consent (Figure 1).

\section{Maximum Strength}

Knee extension torque measurements were performed using an isokinetic dynamometer (Humac Norm II, CSMI, USA). The participant was positioned seated, and knee aligned with the rotation axis of the dynamometer. After a warm-up with five progressive repetitions, the test was carried out in concentric mode with five repetitions of knee extension at $30 \%$ s. The peak torque isokinetic (PT-ISK) was defined as the highest torque value observed. The peak torque angle (PTA) was expressed as the

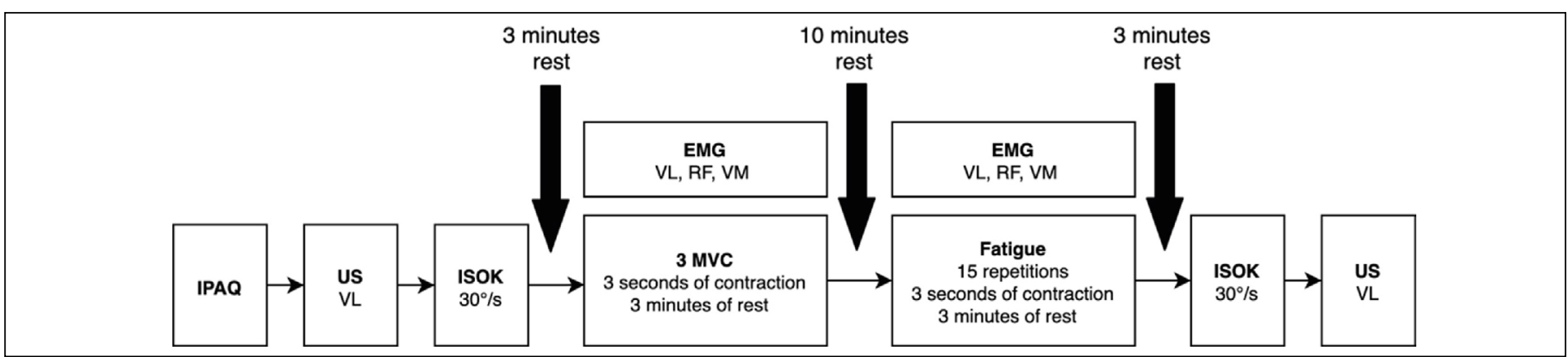

Figure 1. Assessments performed during data collection. International Physical Activity Questionnaire (IPAQ), ultrasound image at rest (US), isokinetic test (ISOK), electromyography (EMG), vastus lateralis (VL), rectus femoris (RF), vastus medialis (VM), isometric maximum voluntary contraction (MVC). 
angle recorded at the time of PT-ISK. Then, after a 3 min rest interval, MVCs of knee extension were performed. Subjects were instructed to extend the knee "as fast and hard as possible" at the command of the evaluator and to keep the muscle contraction until verbal instruction. Two submaximal repetitions were carried out as familiarization and warm-up. The assessment consisted of three MVCs lasting three seconds, performed at the joint position of PTA, and a 3 min rest between each test. During the procedure, the volunteers used a soccer shin guard to avoid discomfort and reduce the complacency of the dynamometer padding. Only the repetition with the maximum isometric torque value (PT-MVC) was used for analysis. The isokinetic and isometric assessments were conducted before (PRE) and after (POST) the fatigue protocol.

\section{Muscle fatigue protocol}

After 10 min interval from isometric test, the participants performed a fatigue protocol consisting of 15 MVCs. Each MVC lasted three seconds, with a 3 seconds rest between each MVC. Pilot tests demonstrated that this protocol was sufficient to generate acute fatigue with reductions of up to $50 \%$ in PT-ISK.

\section{Muscular architecture}

To measure the muscle architecture variables, an ultrasound device (ALOKA, SSD-900, Japan) was used in brightness mode, with a linear transducer of five centimeters and $7.5 \mathrm{MHz}$. Resting images of the vastus lateralis $(\mathrm{VL})$ were taken with the participant lying supine with the knee and hip completely extended. ${ }^{26}$ The transducer was positioned halfway between the greater trochanter and the lateral femoral epicondyle. The images were also obtained PRE and POST. The images were analyzed using the software Image-J.21 Thus, muscle thickness (MT), fascicle length (FL), and fascicle angle (FA) were measured. The FL was estimated through trigonometric relationships ${ }^{27}$ (Figure 2).

\section{Quadriceps surface electromyography}

The EMG signal was measured (EMG 830c, EMG System do Brazil) using disposable Ag/AgCl electrodes (RedDot, 3M Corp. USA) positioned on the $V L$, rectus femoris (RF), and vastus medialis (VM) muscles during the isometric tests. The reference electrode was positioned on the lateral epicondyle of the humerus. Instrumentation and preparation of electrode placement sites followed the recommendations of SENIAM. ${ }^{28}$ The signals were acquired with a sampling frequency of $1 \mathrm{KHz}$ and bandpass filtered of $20-500 \mathrm{~Hz}$.

\section{Calculation of RTD and MDF}

All calculations were done using Matlab 2014 (Mathworks Inc., USA). RTD was determined from MVC test curves for the fixed time ranges of

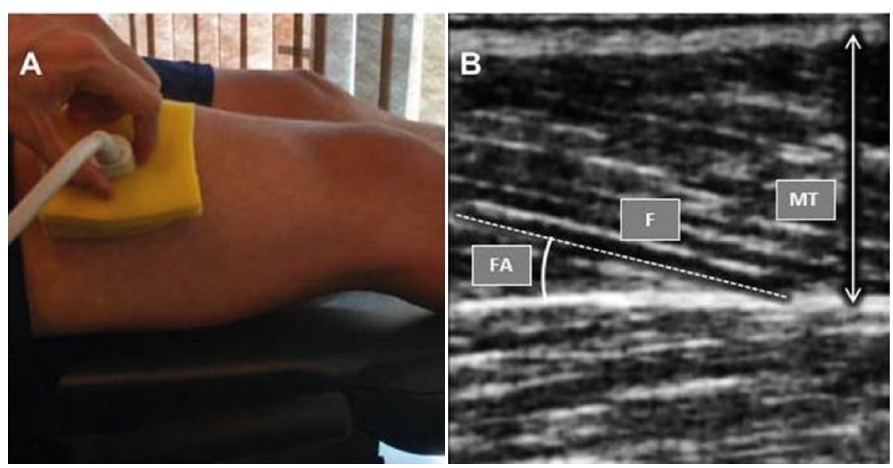

Figure 2. Ultrasound image from vastus lateralis muscle. On the left side, the image shows the place where the ultrasound images were acquired. The image on the right side shows an example of the obtained image. The dashed line represents a fascicle (F), the line with arrows represents the muscular thickness (MT), and the angle represents the fascicle angle (FA).
0-50, 0-100, 0-150, 0-200, and 0-250ms (RTD50, RTD100, RTD150, RTD200, RTD250) (Figure 3A) calculated using Equation 1.

\begin{tabular}{|l|}
\hline Equation $1 \quad R T D=\frac{\Delta \text { torque }}{\Delta \text { time }}$ \\
\hline
\end{tabular}

The signal onset was determined at $1 \mathrm{Nm}$ and confirmed visually by the same experienced evaluator. Instantaneous RTD was obtained by the first derivative of torque for determination of MRTD (Figure 3B). RTDs were calculated in absolute and normalized terms by PT-MVC for the corresponding repetitions and later expressed in relation to the PT-MVC value obtained before the fatigue protocol. The EMG and isometric torque were synchronized offline after the assessments. The EMG was analyzed in a window of two seconds during the plateau of the torque curve. The EMG was filtered to reduce electrical network noise ${ }^{29}$ and then analyzed in the frequency domain. MDF was calculated and used as muscle fatigue indicator.

\section{Statistical Analysis}

All variables have shown normal distribution (Shapiro-Wilk, $p>$ 0.05). To verify the effects of fatigue on PT-ISK, PTA, and the muscle architecture variables obtained in the PRE and POST, separate paired $t$ tests were used. To analyze PT-MVC, RTDs, MDF, MT, FL, and FA measured during the fatigue protocol, the mean of the first three (START, $1^{\text {st }}$ to $3^{\text {rd }}$ repetition) and the last three repetitions (END, $13^{\text {th }}$ to $15^{\text {th }}$ repetition).

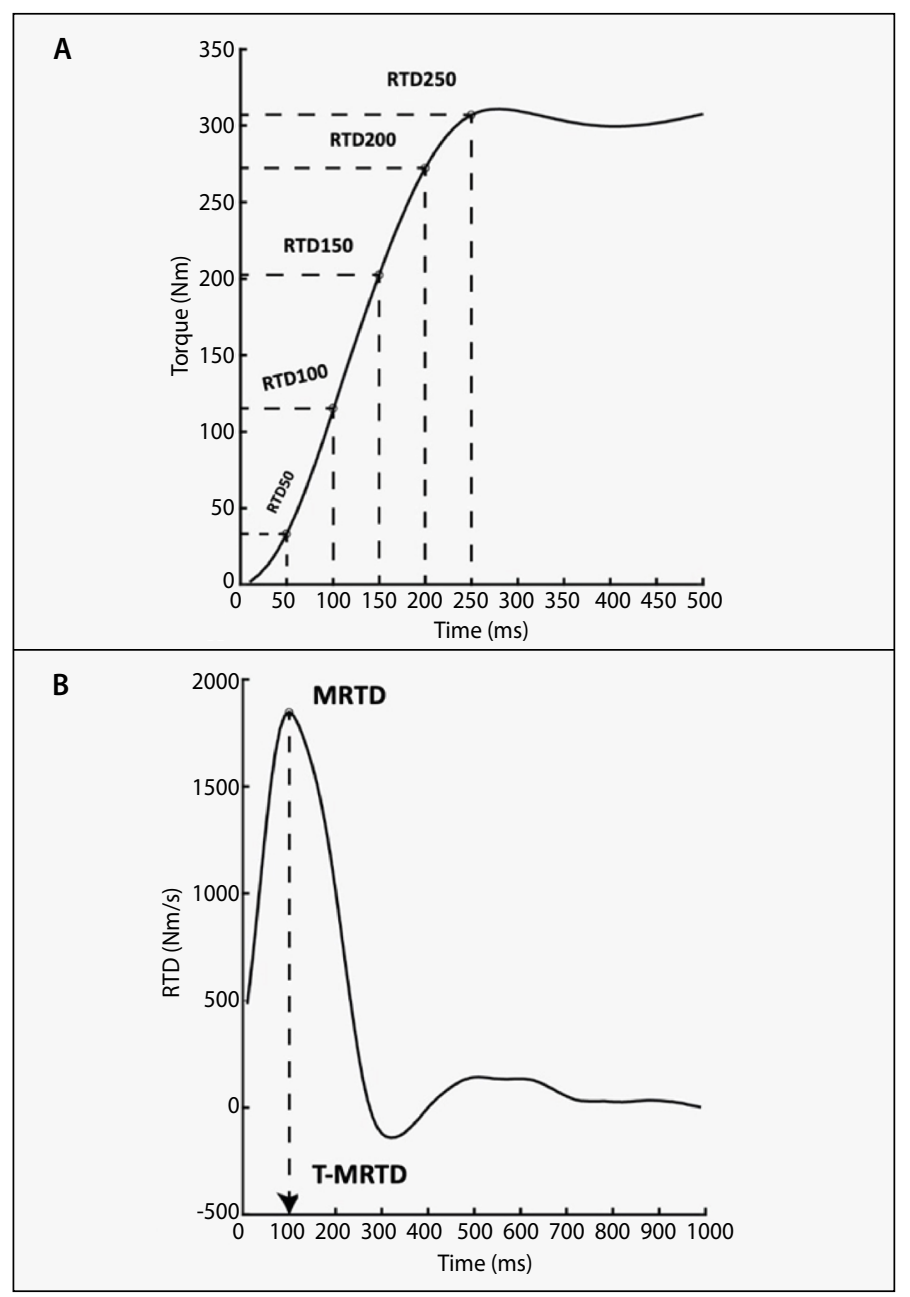

Figure 3. Torque vs. time curve obtained during the isometric assessment. (A) Torque curve used during the isometric assessment. Each test lasted three seconds, but only the first $500 \mathrm{~ms}$ are represented. The rate of torque development (RTD) of this study were depicted in the image. (B) Instantaneous RTD curve obtained by the first derivative of the torque curve. The maximum RTD value (MRTD) and the associated time (T-MRTD) were also shown. 
The START and END values were compared through paired $t$-tests. For the effect size, $d$ statistic was adopted and classified as: trivial $(\leq 0.2)$, small (0.2-0.5), moderate (0.51-0.8), or large (>0.8) effect. ${ }^{30}$ All tests were calculated by means of the SPSS software (IBM SPSS Inc., version 19, (hicago, IL, USA) and the graphs made through the Graphpad Prism (GraphPad Software Inc, version 5, La Jola, CA, USA). The standard value established for the level of significance was $p<0.05$.

\section{RESULTS}

PT-ISK, PTA, MT, FL, and FA measured before and after the fatigue protocol are shown in Table 1. Only PT-ISK ( $p<0.001, d=1.47$ ) revealed significant difference between the PRE and POST moments of the fatigue protocol. During the fatigue protocol, significant reductions were observed in PT-MVC from $269.5 \pm 45.63 \mathrm{Nm}$ to $220.49 \pm 46.94 \mathrm{Nm}(-18 \%, \mathrm{p}<0.002$, $d=1.05$ ). The same pattern was observed for all absolute RTDs (Table 2). However, no significant differences were found for normalized RTDs (Table 3).

Table 1. Peak isokinetic torque values and peak torque angle of knee extensors and muscle architecture before and after muscle fatigue.

\begin{tabular}{c|c|c|c|c}
\hline & Pre & Post & p-value & Cohen d \\
\hline PT-ISK $(\mathrm{Nm})$ & $239.0 \pm 47.91$ & $177.3 \pm 34.96$ & $<0.001$ & 1.47 \\
\hline PTA $\left(^{\circ}\right)$ & $77.7 \pm 9.20$ & $81.1 \pm 10.78$ & 0.15 & 0.33 \\
\hline MT $(\mathrm{mm})$ & $24.7 \pm 3.42$ & $25.7 \pm 3.61$ & 0.12 & 0.30 \\
\hline FL $(\mathrm{mm})$ & $85.1 \pm 14.98$ & $96.0 \pm 25.57$ & 0.05 & 0.52 \\
\hline FA $\left(^{\circ}\right)$ & $17.4 \pm 2.48$ & $16.3 \pm 3.61$ & 0.16 & 0.33 \\
\hline
\end{tabular}

Peak isokinetic torque (PT-ISK). Peak Torque Angle (PTA). Muscle Thickness (MT). Fascicle Length (FL). Fascicle Angle (FA).

Table 2. Absolute RTD values at the beginning and at the end of the fatigue protocol expressed as a percentage of PT-MVC performed before the fatigue protocol.

\begin{tabular}{c|c|c|c|c}
\hline & Start & End & p-value & Cohen d \\
\hline RTD50 (\%) & $0.66 \pm 0.24$ & $0.55 \pm 0.24$ & 0.004 & 0.45 \\
\hline RTD100 (\%) & $0.71 \pm 0.20$ & $0.57 \pm 0.22$ & $<0.001$ & 0.66 \\
\hline RTD150 (\%) & $0.73 \pm 0.18$ & $0.58 \pm 0.20$ & $<0.001$ & 0.81 \\
\hline RTD200 (\%) & $0.75 \pm 0.16$ & $0.59 \pm 0.17$ & $<0.001$ & 0.96 \\
\hline RTD250 (\%) & $0.77 \pm 0.16$ & $0.61 \pm 0.16$ & $<0.001$ & 1.00 \\
\hline MRTD (\%) & $0.80 \pm 0.11$ & $0.61 \pm 0.16$ & $<0.001$ & 1.38 \\
\hline
\end{tabular}

START: value obtained by the mean of the first three repetitions in the fatigue protocol. END: value obtained by the mean of the last three repetitions in the fatigue protocol.

Table 3. Normalized RTD values at the beginning and at the end of the fatigue protocol expressed as a percentage of PT-MVC of the same repetition in which RTD was calculated.

\begin{tabular}{c|c|c|c|c}
\hline & Start & End & p-value & Cohen d \\
\hline RTD50 (\%) & $1.11 \pm 0.36$ & $1.13 \pm 0.49$ & 0.75 & 0.05 \\
\hline RTD100 (\%) & $2.09 \pm 0.70$ & $2.05 \pm 0.91$ & 0.77 & 0.05 \\
\hline RTD150 (\%) & $2.60 \pm 0.82$ & $2.50 \pm 1.02$ & 0.47 & 0.11 \\
\hline RTD200 (\%) & $2.71 \pm 0.80$ & $2.58 \pm 0.92$ & 0.40 & 0.15 \\
\hline RTD250 (\%) & $2.60 \pm 0.67$ & $2.51 \pm 0.76$ & 0.46 & 0.13 \\
\hline MRTD (\%) & $3.89 \pm 0.95$ & $3.66 \pm 1.30$ & 0.27 & 0.20 \\
\hline
\end{tabular}

START: value obtained by the mean of the first three repetitions in the fatigue protocol. END: value obtained by the mean of the last three repetitions in the fatigue protocol.
The VL $(p=0.022, d=0.41)$, RF $(p<0.001, d=1.32)$ and VM $(p<0.001, d=0.58)$ muscles decreased the MDF values significantly during the fatigue protocol (Figure 4).

\section{DISCUSSION}

The aim of this study was to investigate the acute effect of muscle fatigue on RTD and VL muscle architecture. As expected, there was a significant decrease in maximum strength and MDF of quadriceps muscles, indicating the presence of fatigue. ${ }^{18}$ Similarly, absolute RTDs were decreased, but not the normalized explosive strength. A few studies verified the effect of fatigue over a set of intermittent knee extension MVCs. ${ }^{7,19}$ Boccia et al. ${ }^{7}$ studied the effect of 15 intermittent MVCs for knee extension lasting three and a five-second interval, and found significant reductions of 19\% and 20\%, respectively, in PT-MVC and MRTD. As for the other analyzed RTDs, only RTD50 showed no significant difference. However, when the values were normalized by PT-MVC, no significant difference was observed in RTDs. These findings corroborate the decrease in PT-MVC (18\%) and MRTD (23\%) found in the present study, as well as the stabilization of normalized RTD values.

Buckthorpe et al. ${ }^{19}$ investigated the effect of fatigue on the contractile characteristics of knee extensors over 10 sets of five MVCs, lasting three seconds and with a two-second interval, interspersed by a five-second interval between sets. In addition to RTD, muscle activation was measured my means of EMG in the initial moments of contraction, in windows of up to $150 \mathrm{~ms}$. In the interval between sets, a contraction caused by electrical stimulation of the femoral nerve was performed to follow the intrinsic contractile characteristics of the knee extensors, dissociated from neural control. At the end of the protocol, both PT-MVC and RTDs showed a significant reduction, and the proportion of reduction was higher for RTDs (47-56\%) than for PT-MVC (42\%). The normalized RTD in the electrically stimulated contractions did not change, indicating that the intrinsic characteristics of maximum strength and explosive strength of the knee extensors remained proportional.

The differences between the studies by Boccia et al. ${ }^{7}$ and Buckthorpe et al. ${ }^{19}$ may be attributed to the volume of repetitions employed. While Boccia et al. ${ }^{7}$ used 15 intermittent MVCs, Buckthorpe et al. ${ }^{19}$ applied 50 MVCs interspersed with electrically evoked contractions. It is possible that fatigue provoked by a larger volume of MVC produce effects beyond the concomitant reduction in maximum strength and RTD, as revealed by Buchtorpe et al. ${ }^{19}$ As in Boccia et al. ${ }^{7}, 15$ intermittent MVCs were used in the present investigation. This protocol was chosen because its volume would be closer to the exposure time commonly practiced in sports, and pilot studies have exhibited its capability of reducing up to $50 \%$ of PT-MVC.

The architectural characteristics of the muscles are considered determinants of strength production..$^{20}$ Acute changes in the $\mathrm{VL}$ architecture

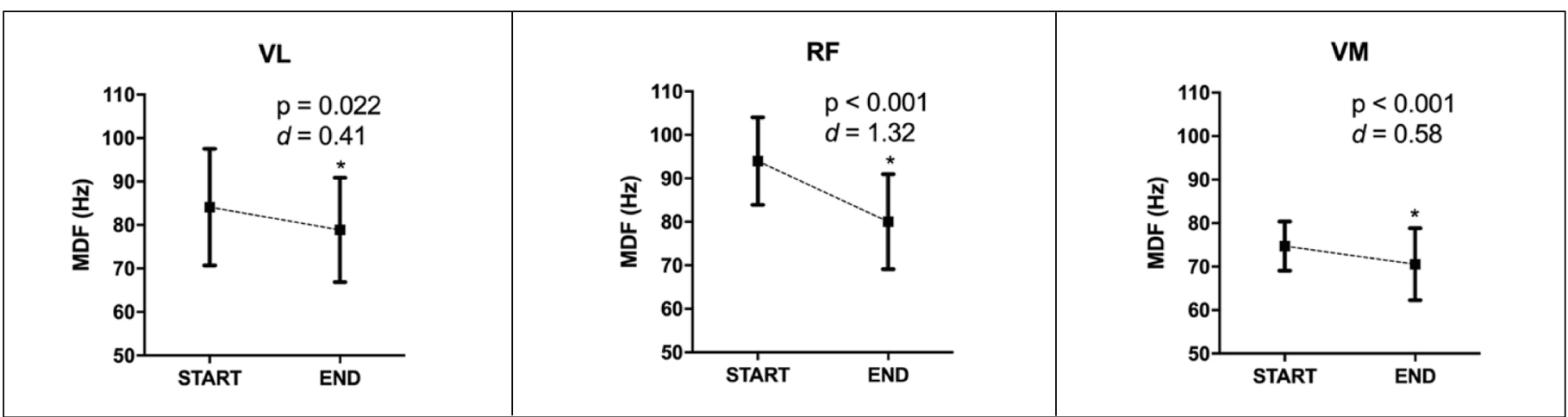

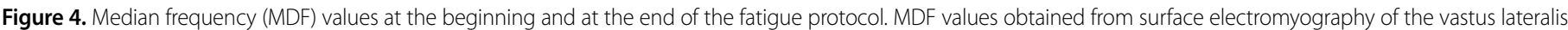
$(V L)$, rectus femoris (RF) and vastus medialis (VM) in the first three (START) and in the last three repetitions (END). 
resulting from fatigue have been reported previously. ${ }^{22,23}$ However, in the present study, no significant changes were observed in any of the investigated variables of muscle architecture. Csapo et al. ${ }^{22}$ reported significant 1\% decrease in FL, 10\% increase in FA and 4\% increase in MT of the $V L$ after performing the maximum number of repetitions possible in a unilateral leg press. Brancaccio et al. ${ }^{23}$ observed an increase in MT and FA after a maximum incremental test on a cycle ergometer with an average duration of 18 min, but the FL was not evaluated. Both studies suggested that blood influx and the onset of an inflammatory process caused an increase in MT of the $V L$, resulting in the observed morphological changes. ${ }^{22,23}$ Mitsukawa et al. ${ }^{24}$ found an increase in FL and a decrease in FA in the lateral gastrocnemius and soleus muscles after 60 plantar flexion MVCs. Although MT has not been measured, the decrease in FA may be an indication that changes were not accompanied by edema. ${ }^{20}$ Taken together, those results suggest that higher volumes of exercise are required for architectural changes to occur.

An important limitation of the present study was the FL calculated trigonometrically through FA and MT. Thus, increases in MT and decreases in FA, even if not significant, may cause changes in FL. The FL presented borderline values when comparing PRE and POST fatigue moments, with moderate effect size. Further studies are warranted so that larger ultrasound probes or panoramic images may be used for more reliable FL measurements. During data collection, some flaws were seen in the EMG signal synchronization system with the isokinetic dynamometer, not allowing for deeper analysis of changes in muscle recruitment pattern and explosive strength capacity.

\section{CONCLUSION}

One set of 15 intermittent MVCs was able to produce significant fatigue in the knee extensor muscles. The reduction in explosive capacity occurred concurrently with a decrease in maximum strength. This fact was reinforced when the fatigue did not provoke changes in normalized RTD. Further studies should investigate different exercise volumes and intensities for the production of fatigue, focusing on neural changes.

\section{ACKNOWLEDGEMENTS}

Part of this study was performed with the support of the Coordenação de Aperfeiçoamento de Pessoal de Nível Superior - Brazil [Coordination for the Improvement of Higher Education Personnel] (CAPES) - Financing code 001.

All authors declare no potential conflict of interest related to this article

AUTHORS' CONTRIBUTIONS: Each author made significant individual contributions to this manuscript. MMS: design, writing the article, and data collection; CTL: design, writing the article, data collection and revision; UFG: design, data collection and revision; RG: design, writing the article and revision; CGO: design, writing the article and revision; LMS: data collection and revision; SCS: design, writing the article, intellectual concept, data collection and revision; VC: design, writing the article, intellectual concept, data collection and revision.

\section{REFERENCES}

1. Francis P, Lyons M, Piasecki M, Mc Phee J, Hind K, Jakeman P. Measurement of muscle health in aging. Biogerontology. 2017;18(6):901-11.

2. Maffiuletti NA, Aagaard P, Blazevich AJ, Folland J, Tillin N, Duchateau J. Rate of force development: physiological and methodological considerations. European journal of applied physiology. 2016;116(6):1091-116.

3. Rodríguez-Rosell D, Pareja-Blanco F, Aagaard P, González-Badillo JJ. Physiological and methodological aspects of rate of force development assessment in human skeletal muscle. Clinical physiology and functional imaging. 2018;38(5):743-62.

4. Buckthorpe M, Roi GS. The time has come to incorporate a greater focus on rate of force development training in the sports injury rehabilitation process. Muscles, ligaments and tendons journal. 2017;7(3):435.

5. Dapena J, Chung C. Vertical and radial motions of the body during the take-off phase of high jumping. Medicine and science in sports and exercise. 1988;20(3):290.

6. Kuitunen S, Komi PV, Kyröläinen H. Knee and ankle joint stiffness in sprint running. Medicine and science in sports and exercise. 2002;34(1):166.

7. Boccia G, Dardanello D, Tarperi C, Festa L, La Torre A, Pellegrini B, et al. Fatigue-induced dissociation between rate of force development and maximal force across repeated rapid contractions. Human Movement Science. 2017;54:267-75

8. Haff GG, Ruben RP, Lider J, Twine C, Cormie P. A comparison of methods for determining the rate of force development during isometric midthigh clean pulls. The Journal of Strength \& Conditioning Research. 2015;29(2):386-95.

9. Thompson BJ, Ryan ED, Sobolewski EJ, Smith DB, Akehi K, Conchola EC, et al. Relationships between rapid isometric torque characteristics and vertical jump performance in Division I collegiate American football players: Influence of body mass normalization. The Journal of Strength \& Conditioning Research. 2013;27(10):2737-42.

10. Djordjevic D, Uygur M. Methodological considerations in the calculation of the rate of force development scaling factor. Physiological measurement. 2017;39(1):015001.

11. Jenkins ND, Buckner SL, Bergstrom HC, Cochrane KC, Goldsmith JA, Housh TJ, et al. Reliability and relationships among handgrip strength, leg extensor strength and power, and balance in older men. Experimental gerontology. 2014;58:47-50.

12. Dideriksen JL, Del Vecchio A, Farina D. Neural and muscular determinants of maximal rate of force development. Journal of Neurophysiology. 2020;123(1):149-57.

13. Folland J, Buckthorpe M, Hannah R. Human capacity for explosive force production: neural and contractile determinants. Scandinavian Journal of Medicine \& Science in Sports. 2014;24(6):894-906.

14. Andersen LL, Andersen JL, Zebis MK, Aagaard P. Early and late rate of force development: differential adaptive responses to resistance training? Scandinavian journal of medicine \& science in sports. 2010;20(1):e162-9.
15. Ertl P, Kruse A, Tilp M. Detecting fatigue thresholds from electromyographic signals: A systematic review on approaches and methodologies. Journal of Electromyography and Kinesiology. 2016;30:216-30.

16. Cheng AJ, Place N, Westerblad H. Molecular basis for exercise-induced fatigue: the importance of strictly controlled cellular Ca2+ handling. Cold Spring Harbor perspectives in medicine. 2018;8(2):a029710.

17. Bandpei MAM, Rahmani N, Majdoleslam B, Abdollahi I, Ali SS, Ahmad A. Reliability of surface electromyography in the assessment of paraspinal muscle fatigue: an updated systematic review. Journal of manipulative and physiological therapeutics. 2014;37(7):510-21.

18. Merletti R, Parker PJ. Electromyography: physiology, engineering, and non-invasive applications. Vol. 11. John Wiley \& Sons; 2004.

19. Buckthorpe M, Pain MT, Folland JP. Central fatigue contributes to the greater reductions in explosive than maximal strength with high-intensity fatigue. Experimental Physiology. 2014;99(7):964-73.

20. Blazevich AJ, Gill ND, Zhou S. Intra-and intermuscular variation in human quadriceps femoris architecture assessed in vivo. Journal of anatomy. 2006;209(3):289-310

21. Csapo R, Alegre LM, Baron R. Time kinetics of acute changes in muscle architecture in response to resistance exercise. Journal of Science and Medicine in Sport. 2011;14(3):270-4.

22. Brancaccio P, Limongelli FM, D'Aponte A, Narici M, Maffulli N. Changes in skeletal muscle architecture following a cycloergometer test to exhaustion in athletes. Journal of Science and Medicine in Sport. 2008;11(6):538-41.

23. Mitsukawa N, Sugisaki N, Kanehisa H, Fukunaga T, Kawakami Y. Fatigue-related changes in fascicle-tendon geometry over repeated contractions: Difference between synergist muscles. Muscle \& Nerve: Official Journal of the American Association of Electrodiagnostic Medicine. 2009;40(3):395-401.

24. Matsudo S, Araúio T, Matsudo T, Andrade D, Andrade E, Oliveira LC, et al. Questinário internacional de atividade f1 sica (IPAQ): estudo de validade e reprodutibilidade no Brasil. Rev Bras Ativ Saude. 2001;6(2):5-18.

25. Blazevich AJ, Cannavan D, Horne S, Coleman DR, Aagaard P. Changes in muscle force-length properties affect the early rise of force in vivo. Muscle \& nerve. 2009;39(4):512-20.

26. Schindelin J, Rueden CT, Hiner MC, Eliceiri KW. The Image ecosystem: An open platform for biomedical image analysis. Molecular reproduction and development. 2015;82(7-8):518-29.

27. Brennan SF, Cresswell AG, Farris DJ, Lichtwark GA. In vivo fascicle length measurements via Bmode ultrasound imaging with single vs dual transducer arrangements. Journal of biomechanics. 2017;64:240-4.

28. Hermes HJ, Freriks B, Disselhorst-Klug C, Rau G. Development of recommendations for SEMG sensors and sensor placement procedures. Journal of Electromyography Kinesiology. 2000;10:361-74.

29. Mello RG, Oliveira LF, Nadal J. Digital Butterworth filter for subtracting noise from low magnitude surface electromyogram. Computer methods and programs in biomedicine. 2007;87(1):28-35.

30. Cohen J. Statistical power analysis for the behavioral sciences. 2nd ed. Cambridge, Massachusetts: Academic press; 2013 